\title{
Why Does Velocity Matter?
}

\author{
DANIEL L. THORNTON
}

$\mathrm{T}$

HE significant decline in the income velocity of money during 1982 and in the first quarter of 1983 has engendered confusion and controversy. ${ }^{1}$ Amid this controversy, little attention has been paid to the more fundamental role velocity plays in macroeconomics and, hence, about its potential and actual importance in the conduct of monetary policy. This article sets forth the concept of income velocity and illustrates the potential effects of a change in velocity for monetary policy.

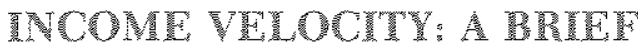 OVERWIIE}

Irving Fisher's famous "equation of exchange" primarily was responsible for the prominent role of income velocity in macroeconomic analysis. ${ }^{2}$ In its most rudimentary form, the equation of exchange can be written as the identity given by equation $I$ in table 1 . Here, $M$ and $Y$ denote the nominal money stock (however defined) and nominal GNP, respectively, and V represents income velocity, the average number of times each unit of nominal money is used to support nominal GNP. Nominal GNP, in turn, can be represented by the average level of prices, $P$, times real

Daniel $L$. Thamton is a senior economist at the Federal Reserve Bank of St. Louis. John G. Schulte provided research assistance.

${ }^{\mathrm{t}}$ The decline in velocity was a persistent concem of the Federal Open Market Committee (FOMC) in the conduct of monetary policy during 1982 and contributed to the Committer s decision to suspend the use of $\mathrm{MI}$ ats an intermediate policy target in October 1982. See Daniel L. Thornton, "The FOMC in 1982: Deemphasizing M1," this Retiew (June/July 1983), pp. 26-35.

${ }^{2}$ Irving Fisher (assisted by Harry G. Brown) The Publishing Power of Money: Its Determination and Relation to Credit, Interest and Crises (MacMilan, 1911).
GNP, X. In this form, the equation of exchange is an accounting identity equating the nominal money stock multiplied by the number of times each unit turns over to nominal output, that is, $\mathrm{V}=\mathrm{Y} / \mathrm{M}$. In this form, the equation is of little practical use since there is one equation and four unknown quantities, $\mathrm{M}, \mathrm{V}, \mathrm{P}$ and $\mathrm{X}$.

\section{Making the Equation of Exchange Useful}

Fisher argued, however, that the level of velocity is determined by a number of social and economic factors. ${ }^{3}$ He argued further that these factors tend to be relatively stable so that velocity could be treated as a constant, $\overline{\mathrm{V}}{ }^{4}$ Under this assumption, equation 1 ceases to be an identity and becomes Fisher's useful equation of exchange (equation 2, table 1). If $V$ is constant and $M$ is controlled exogenously by the monetary authority, nominal GNP can be determined - indeed, con-

\footnotetext{
${ }^{3}$ Money was viewed primarily as a medium of exchange necessitated by the lack of symchronization between the sale of one good and the purchase of another. Thes, the proportion of income held on average) in the form of money balances was determined by institutional factors that determined the pattern of payments and receipts. A discussion of this can be found in most macroeconomics textbooks.

${ }^{4}$ Actually, the classical economists never considered $V$ to be a constant in the sense of unchangeable. Irdeed, they recognized the effects of interest rates and price expectations on velocity; how ever, they generally believed that such factors would be relatively unimportant over the long run. For a good disclassion of these issues, see Laurence Harris, Monetary Theory (MoGraw-Hill, 1981), chapter 6

${ }^{5}$ Although they stem fron different theoretical approaches, Fisher's equation of exchange is similar to the "Cambridge cash balance equation" of Marshall and Pigon. See Alfred Marshall, Money, Credit and Commerce (MacMillan, 1923); and A. C. Pigow, "The Value of Money," Quarterly Joumal of Economics (November 1917), pp. 38-65.
} 


\section{Table 1}

\section{Various Forms of the Equation of Exchange}
(1) $M V=P X$
(2) $M V=Y$
(3) $M V=\cdot P X$
(4) $\mathrm{M}+\mathrm{V}=\mathrm{Y}=\mathrm{p}, \mathrm{x}$
(5) $\hat{p}=\mathrm{M}+\hat{\mathrm{N}}-\hat{\mathrm{x}}$

trolled - through monetary policy. ${ }^{6}$ That is, for any $\bar{V}$, the monetary authority can obtain any $\mathrm{Y}$ it desires simply by setting $M$ at the appropriate level. If a primary goal of policy is to stabilize nominal income growth, a constant velocity would give the monetary authority the means to achieve this goal by controlling money growth. ${ }^{7}$ Of course, it is impossible from this relationship to determine the separate effects of changes in $M$ on real output and prices.

\section{The Quanity Theory of Money}

If real output is determined independently of the stock of nominal money in the long run, selecting the money stock is tantamount to determining the price level. This is essentially the position of the classical economists, who argued that the amount of real output is determined by the "real" side of the market (e.g., factors of production, technology and relative prices). In the most elementary form of the equation, output is fixed at the full-employment level, $\overline{\mathrm{X}}$. With this added assumption, Fisher's equation of exchange becomes the so-called crude quantity theory of money, given by equation 3 of table 1 . With $V$ and $X$ constant, there is a direct, proportional link between money and the price

\footnotetext{
${ }^{6}$ Money is assumed to be largely exogenous. Both classical and neoclassical writers acknowledged the feedback of prices to money. Modern writers like Friedman and Schwartz consider money to be "for all practical purposes" exogenous in the serse that it can be controlled by the monetary authority. See Milton Friedman and Anna). Schwartz, Monetary Statistics of the United States (National Barean of Economic Research, 1970), p. 124.

7The goals of economic policy as set forth in the Full-Employment Act of 1946. are (1) full employment, (2) price level stability, (3) equilibrium in the balance of payments and (4) a high rate of economic growth. The first two of these are reiterated in the Humphrey-Hawkins Act. Since $Y=P, X$, the first two objectives amount to stabilizing nominal GNP.
}

Table 2

Growth Rates of Real Output and Velocity: II/1954-IV/1981

\begin{tabular}{|c|c|c|c|c|}
\hline County & 101 & P & $v$ & $x$ \\
\hline United States & $48 \%$ & $45 \%$ & $3.4 \%$ & $34 \%$ \\
\hline Gernany & 79 & 44 & 05 & 37 \\
\hline Japan? & 15.3 & 5.6 & 05 & 82 \\
\hline United lingtom & 88 & 10.3 & 40 & 21 \\
\hline Canado & 6.9 & 52 & 34 & 4.6 \\
\hline
\end{tabular}

level: if the money stock doubles, the price level will double. $^{8}$

This version of the quantity theory, while appealing because of its simplicity, is of limited use because real output is not constant at the full-employment level; instead it varies over business cycles.

Thus, a more sophisticated quantity theory of money is a long-run (secular) theory of the relationship between money and prices. Under this more general theory, changes in the money stock may result in changes in real output or prices (or both) in the short run, but result primarily in price level changes in the long run (i.e., over business cycles) ${ }^{9}$ Within this expanded framework, the quantity theory conclusion of the close correspondence of money growth and price level movements holds in the long run.

\section{Felocity Is Not a Numerical Consune}

Frequently, velocity is treated erroneously as a numerical constant; however, this restriction is both unnecessary and incorrect. Equation 1 can be written in the useful growth rate form as equation 4 of table 1 . The dots over the variables denote compounded annual growth rates. Velocity need not be constant for

\footnotetext{
"This is the "neutrality of money." Also, there was the closely related "classical dichotomy" between money and output. For a discussion of these points, see Harris, Monetary Theory, chapters 4 and 6; and Don Patinkin, Money, Interest and Prices (Harper and Row, 1965), chapter 8 .

"Furthermore, full employment does not necessarily mean zero unemployment, but is merely a level consistent with stable prices given the structural characteristics of the labor and output markets, including market imperfections. See Milton Friedman, "The Role of Monetary Policy," American Economic Review (March 1968), pp. 1-17, for his concept of the natural rate of unemployment.
} 


\section{Char: I \\ Rate of Price Change minus Rate of Money Growth}

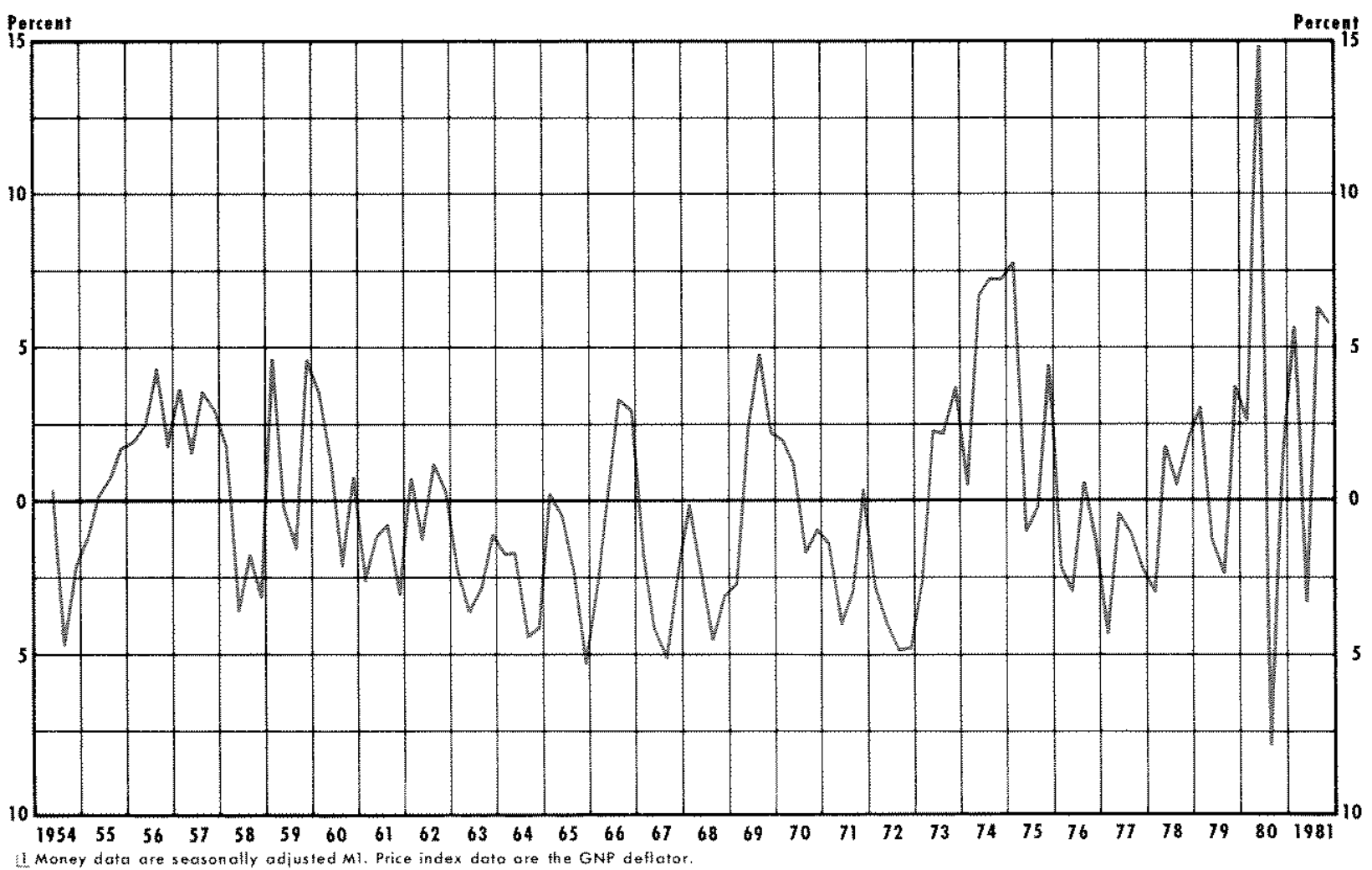

nominal GNP to be controlled through monetary policy; all that is required is that its growth rate be relatively stable. Equation 4 can be rewritten as equation 5 to show that the rate of increase in prices (inflation) is related to money growth. Thus, in the long run, the relative growth rates between money and prices reflect the relative difference between the growth rates of velocity and real output. The slower velocity growth is relative to real output growth, the faster the growth in nominal money can be consistent with stable prices or a low rate of inflation.

If $\dot{\mathrm{V}}$ and $\dot{\mathrm{X}}$ are approximately equal on average, then the rate of inflation will equal approximately the growth rate of money. Basically, this situation has existed in the United States for roughly the past three decades. The average quarter-to-quarter compounded annual rates of growth of Ml velocity and real output from II/1954 to IV/1981 were both 3.4 percent. As a result of the equality between $\dot{V}$ and $\dot{X}, \dot{M} l$ and $\dot{P}$ were equal over this period. Both the implicit price deflators for GNP and M1 increased at an average compounded annual rate of 4.5 percent over this same period. In the short run, however, $\dot{X}$ and $\dot{V}$ deviate from each other; thus, so do $\dot{\mathrm{M}} 1$ and $\dot{\mathrm{P}}$. This is illustrated in chart 1 , which shows the difference between $\dot{P}$ and $\dot{M} I$ for the period.

This long-run, near-equality between $\dot{\mathrm{P}}$ and $\dot{\mathrm{M}} 1$, however, does not hold for all countries. This is shown in table 2 , which shows the average growth of $\dot{V}, \dot{X}, \dot{P}$ and $\mathrm{M} I$ for five countries, including the United States.

\section{VEUOCTY AND MONETARY POLICY}

If one goal of monetary policy is to stabilize nominal GNP growth, policymakers must incorporate velocity considerations into their decisions. There are, how ever, a variety of ways in which velocity can change. These complicate the analysis of velocity movements for policy decisions.

\section{Permanent $\mathrm{V}$. Temporm Changes}

If a change in velocity is known and is permanent, the appropriate policy response is a compensatory 


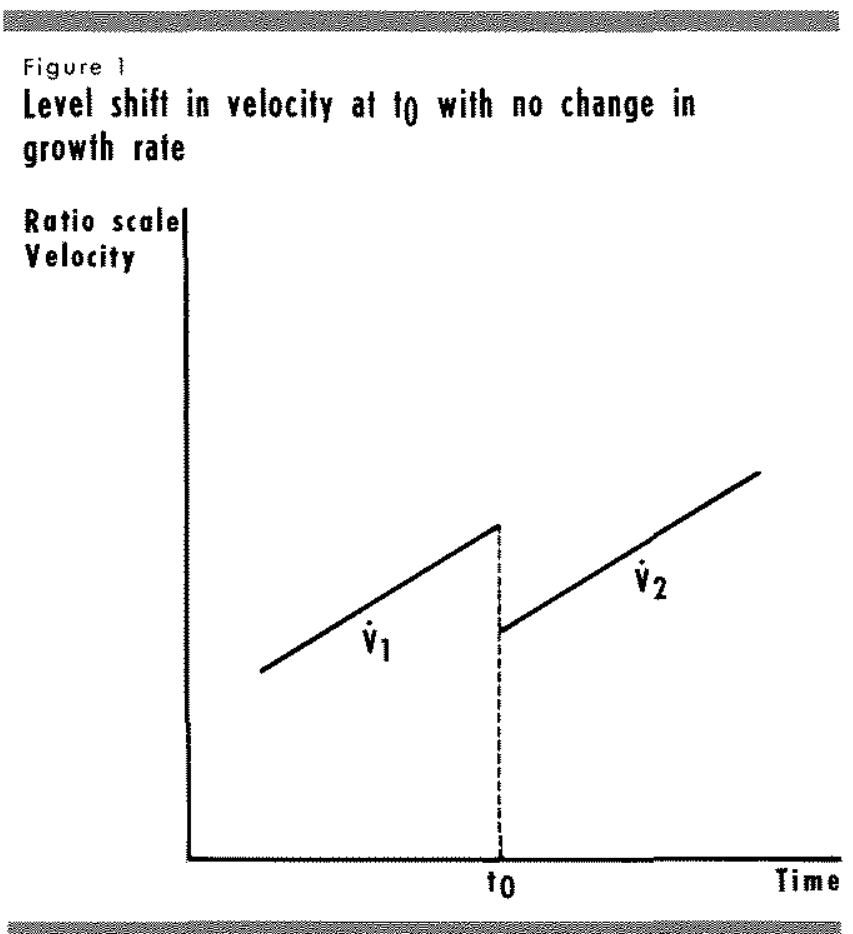

change in money to offset the effects of a velocity change on $\mathrm{Y}^{10}$

If a change is temporary, however, policymakers may decide not to respond to the change because their response may increase rather than reduce the instability of nominal income. For example, suppose that policymakers observe a decline in velocity that they anticipate will reverse itself in the course of a quarter or two. If policymakers want to neutralize the effect of this temporary change on nominal income, they will increase the rate of money growth to keep nominal income growth on course, then reduce money growth later when the velocity change reverses.

Because policymakers are generally uncertain about the timing and extent of such a shift, they may be too aggressive for too long, producing larger swings in nominal income growth than would have occurred otherwise. Such instability need not result inevitably from policy responses to temporary changes in velocity; nevertheless, the danger is there. Thus, if policymakers suspect that the velocity change they observe is temporary, they may choose to ignore it. ${ }^{\text {il }}$

${ }^{10}$ This statement and mueh of the discussion that follows assumes a long-run neutrality of money; that is, changes in the growth rate of money have no lasting effect on the growth rate of real output. If money is not neutral in the long run, both the policy prescriptions and the effects of a failure to respond to velocity changes would differ accordingly.

"For example, at its meeting of November 16, 1982 , the Federal Open Market Committee anticipated that Ml might grow due to a

\section{Decrease in the growth rate of velocity at to}

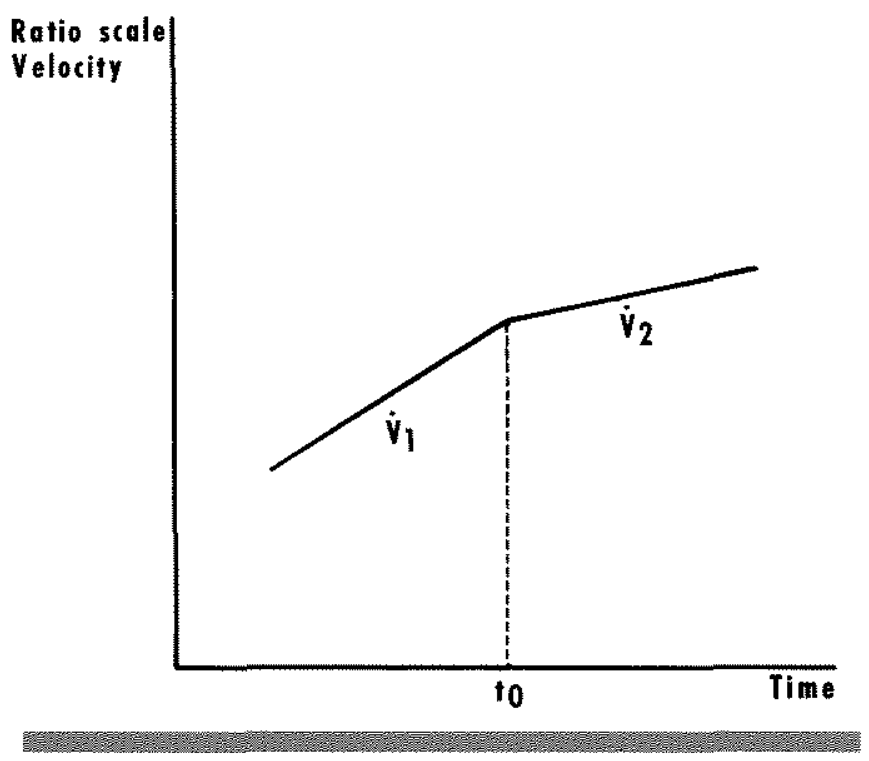

\section{Level Vs. Growth Rate Shifts}

Policymakers also must distinguish between changes in the levels of velocity and changes in its growth rate; the policy response will be different in the two cases. To illustrate this, consider the cases depicted in figure $1^{12.2}$ In both, $\dot{\mathrm{V}}_{1}$ and $\dot{\mathrm{V}}_{2}$ represent the growth rate of velocity before and after the hypothetical change at time $t_{0}$.

In the case of a permanent decline in the level of velocity that leaves the growth rates unaffected $\left(\dot{V}_{1}=\right.$ $\dot{V}_{2}$, a policy response that accelerated the growth of money temporarily until the higher desired level is obtained and then returned money growth to its previous rate would produce an unvarying rate of growth in GNP. In the second case $\left(\dot{\mathrm{V}}_{2}<\dot{\mathrm{V}}_{1}\right)$, a compensatory and permanent increase in the growth rate of money at time $t_{0}$ is necessary to maintain the growth rate of GNP.

If policymakers failed to respond to the velocity changes depicted in figure 1 , the consequences would

temporary buildup of balataces in Ml components for eventual placement in the new money market deposit accounts (MMDAs), which would become effective on December 14,1982 . Thus, the Committee anticipated at short-run decline in velocity resulting from this potential buildup. See "Record of Policy Actions of the FOMC, Federal Reserve Bulletin (fanmary 1983), p. 19 .

${ }^{12}$ A ratio scale for the natural log of velocity is presented in figure 1 so that the growth rates can be represented by the slopes of straight lines. 
Chort 2

Rate of Velocity Change and its Average

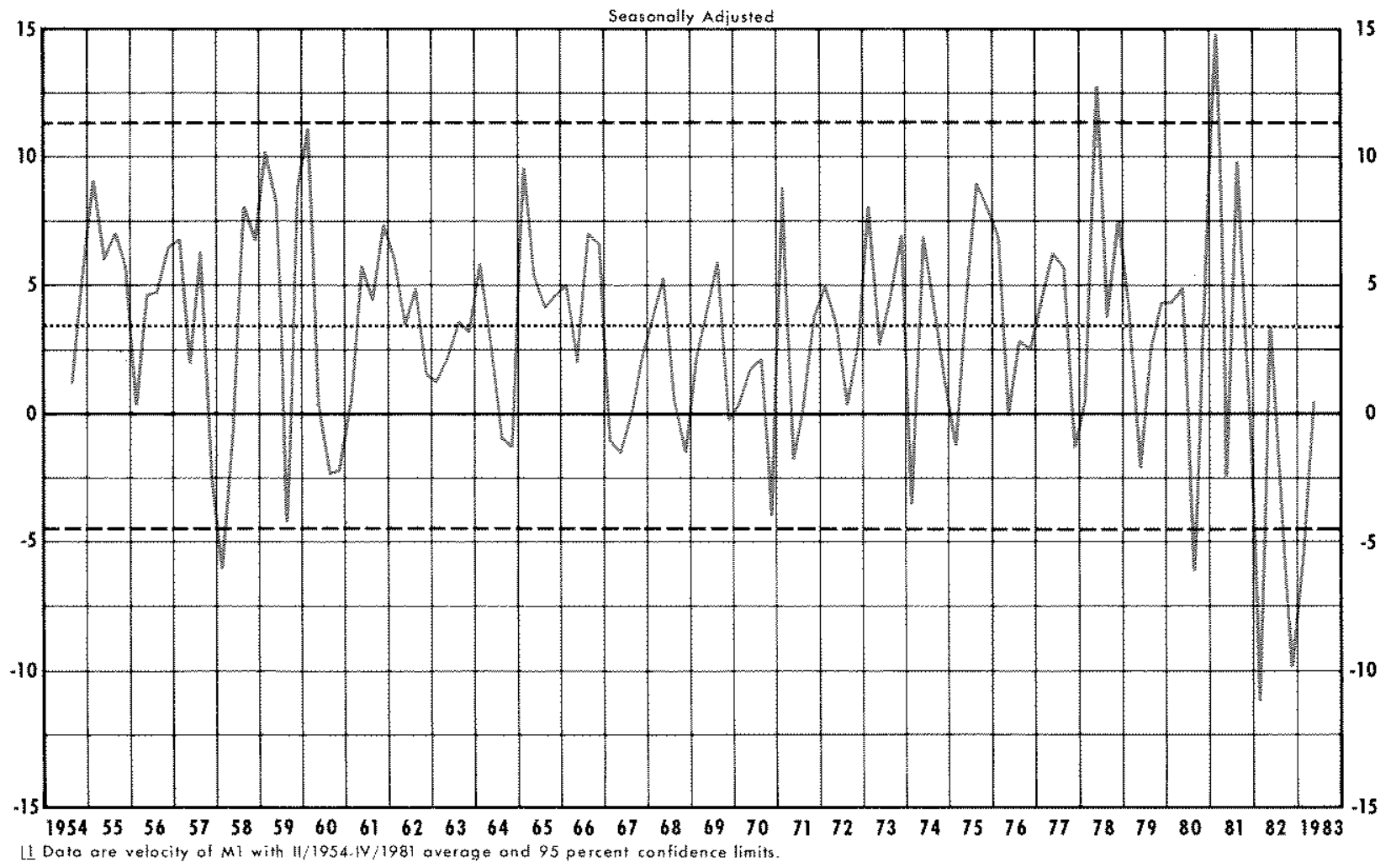

be different in the two cases. In the first (level-shift) case, there would be a temporary reduction in the rate of change of prices or real output, or both. In the long run, however, velocity would return to its former growth rate and, hence, so would the growth of nominal output. In the second case, the growth rate of prices would be lowered permanently; in addition, the growth rate of real output may be lowered temporarily if the monetary authority failed to adjust the growth rate of money in response to a permanent decline in velocity growth.

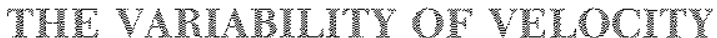

The timing of the policy response to the velocity change, of course, is very important. Unfortunately, it is difficult to determine whether there has been a significant change in velocity, let alone to foresee such a change. Furthermore, it is difficult to differentiate between level and growth rate shifts, and to differentiate between temporary and permanent changes.

In order to see why this might be the case, consider the historical movements in the growth rate of M1 velocity presented in chart 2 . This chart shows the quarter-to-quarter growth rate of $\mathrm{M} 1$ velocity, a horizontal line showing the average growth rate of $\mathrm{MI}$ velocity for the period II/1954-IV/1981, and dashed lines representing plus or minus two standard deviations of the quarter-to-quarter growth rate of velocity from its mean over this period. ${ }^{13}$

It is obvious that the quarter-to-quarter growth rate of velocity is highly variable. Nevertheless, it falls outside the range of plus or minus two standard devia tions in four of the 111 quarters from II/1954-IV/1981. More recently, there bave been three occasions during the last six quarters when the growth rate of velocity has fallen outside of this range. A priori, it is difficult to determine whether these apparent shifts are simply temporary movements in the growth rate associated with a permanent change in the level of velocity, a permanent change in the growth rate, or a temporary change in the growth rate associated with a temporary change in the level. Indeed, it is difficult to know

\footnotetext{
${ }^{13}$ If $\dot{V}$ is nomally distributed, then approximately 95 percent of its observed values should fall within \pm 2 standard deviations.
} 
whether these changes represent a significant change in velocity. It could be that other factors that affect velocity may have caused it to change. Thus, in order to determine whether a policy response is called for, it is necessary to examine the factors that determine velocity.

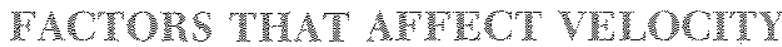

There are a number of factors that can cause velocity to change. ${ }^{14}$ Since increased velocity is simply the ratio of nominal GNP to the stock of money, any factor that causes the stock of money to change relative to nominal output, or vice versa, can produce a change in the level of velocity. Likewise, any factor that causes the growth rate of money to change relative to the growth rate of nominal GNP, or vice versa, will cause the growth rate of velocity to change. Furthermore, since the growth rate of velocity is defined as the percentage change in the level of velocity per unit of time, factors that affect the level of velocity affect the growth rate if they likewise change through time. Thus, the following discussion will be carried out in terms of the level of velocity, unless otherwise stated.

Many of the factors that affect velocity can be analyzed easily by recognizing that velocity changes whenever people alter their holdings of money relative to their income. Factors that cause people to hold less money relative to their income increase velocity, while factors that cause people to increase their money holdings reduce it. For example, if two households have the same income and monthly expenditure patterns but one receives its income once a month while the other receives it twice a month, the latter, all other things constant, will hold less money on average than the one that receives income once a month. Thus, changes in the pattern of receipts and expenditures can produce changes in society's holdings of money relative to income.

\section{Tconoming on Moner Balances}

Other factors that cause individuals to economize on their holdings of money relative to income increase velocity. For example, the increased use of credit cards conld reduce individuals' desires to hold money bal-

itFor discussions of some of these, see John A. Tatom, "Was the 1982 Velocity Decline Unusklal?" this Review (August/September 1983), pe. 5-15; and Willam T. Gavin, "Velocily and Wonetary Targets," Economic Commentary, Federal Reserve Bank of Cleveland (June 6, 1983). ances and, thus, increase velocity. In particular, these and other lines of credit may lessen individuals' desires to hold money as a contingency against uncertainty. ${ }^{15}$

Two of the most commonly cited factors that can cause changes in velocity are changes in real interest rates and expectations of inflation. Increases in the real interest rate tend to cause individuals to hold less money relative to their real income. The same generally will be true of an increase in the expected rate of inflation. Higher expected inflation will cause individuals to economize on their money holdings, raising velocity.

\section{Finnoid Tnnovations}

Financial innovations also can produce velocity changes. In general, innovations that reduce the implicit or explicit cost, or both, of transferring funds from non-transaction to transaction forms (perhaps by giving transaction characteristics to assets not included in M1) tend to increase the velocity of $\mathrm{Ml}$. Therefore, innovations such as money market deposit accounts and money market mutual funds would increase the velocity of Ml to the extent that they lower these costs.

In contrast, innovations that lower the cost of holding $M 1$ relative to non $M I$ assets tend to reduce the velocity of $\mathrm{M} 1$. This could be the case with automatic transfer of savings, negotiable order of withdrawal (NOW), and Super-NOW accounts. ${ }^{16}$ Such innovations, however, may produce a temporary decline in velocity that lasts only until individuals realign their portfolios.

\section{Cuchon Pachers}

Finally, there are a number of factors that can cause velocity to change with cyclical movements in real income (see appendix). They suggest that velocity tends to rise during periods of rising real income and fall during periods of declining real income.

Furthermore, there is considerable evidence that a change in money growth affects nominal income with a

\footnotetext{
${ }^{5}$ For a more detailed discussion, see Mack Ott, "Money, Credit and Velocity," this Retew (May 1982), pp. 21-34. To klate, however, there is litte empirical support for this proposition abotat credit cards.

${ }^{16}$ John A. Tatom, "Recent Financial Innovations: Have They Distorted the Meaning of M1?" this Review (April 1982), pp. 23-35; and John A. Tatom, "Money Market Deposit Accounts, Super" NOW's and Monetary Policy," this Review (March 1983), pp. 516 .
} 
lag that is distributed over several quarters. Thus, an acceleration in money growth will produce a temporary decline in velocity as nominal output temporarily grows at a slower rate than does money. Thus, a decline in velocity associated with a recession can be exacerbated if the monetary authority expands money rapidly in order to stimulate a sluggish economy.

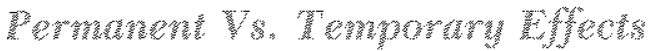

While all the factors mentioned above can affect velocity, they need not produce a lasting effect on its level or on its growth rate. For example, it is commonly recognized that, in a noninflationary environment, in terest rates tend to be procyclical - rising during the expansion phase of the business cycle and declining during the contraction phase. Although the level of velocity and its growth rate can be affected by movements in interest rates, neither need change perma nently; they, like such cyclical movements in interest rates, simply will average out over the course of a business cycle.

Also, financial innovations can have a permanent effect on the level of velocity but, perhaps, only a temporary effect on its growth rate. An innovation that lowers the cost of holding $\mathrm{Ml}$ relative to non-MI assets induces a shift out of non-M1 into Ml assets, permanently lowering $\mathrm{M} 1$ velocity but reducing the growth rate only temporarily. Once the portfolios are realigned, the growth rate of velocity simply may resume its previous path. ${ }^{17}$ Nevertheless, financial innovations can affect the extent to which velocity responds to changes in some of the other factors mentioned above. ${ }^{18}$

\section{Forecaseng Felowin Changes}

Indeed, several economists have suggested recently that the seemingly unusual changes in velocity shown in chart 2 can be accounted for by cyclical movements in velocity and by changes in the inflation rate and interest rates. ${ }^{19}$ This section does not attempt to evalu-

\footnotetext{
${ }^{17}$ For example, if individuals held expectations of inflation over a long period of time because of, say, excessive money growth, they might attempt to realign their portfolios continually in order to economize on money holdings and, as a result, the growth rate of velocity would be positive over this period.

${ }^{18}$ The avalability of more and better substitutes for a commodity tends to increase its own and cross elasticities of demand. Thus, fnancial innovations affect velocity to the extent that they alter velocity's response to the above factors.

${ }^{19}$ See Tatom, "Was the 1982 Velocity Dedine Unusual?"; John $\mathrm{P}$. Judd, "The Recent Decline in Velocity: Instability of Money
}

ate these claims. Instead, the purpose here is to show that even when these factors are accounted for, it is difficult to forecast short-run changes in velocity.

To illustrate this point, the in-sample standard deviation of a model of velocity growth which recently appeared in this Review will be used as an estimate of the true one-quarter-ahead forecast error. The insample standard deviation is used to be conservative, and this model was selected because it incorporates many of the factors discussed above and because it performs well in forecasting velocity growth. ${ }^{20}$ The in-sample standard deviation is about 2.0 percentage points. Thus, after accounting for factors that significantly influence velocity growth, the approximate 95 percent confidence interval for the forecast of velocity growth, $\dot{\mathrm{V}}_{\mathrm{f}}$, will be $\dot{\mathrm{V}}_{\mathrm{f}} \pm 2(2.0)$ or $\dot{\mathrm{V}}_{\mathrm{f}} \pm 4 .^{21}$ This implies a fairly large margin for error. For example, if the forecast for velocity growth is 5 percent, then, loosely interpreted, actual velocity growth can be expected to be between 1 and 9 percent with high probability. This sizable margin for error demonstrates that the monetary authority will generally find it difficult to stabilize nominal output growth in the short run by offsetting short-run changes in velocity. ${ }^{22}$

Furthermore, the sizable error makes it difficult to determine whether a significant change in velocity has taken place. It takes a fairly large change in velocity growth to be significant enough to be considered unusual. Of course, the problems of discriminating between permanent and temporary shifts and between level and growth rate changes remain.

Demand or Inflation?" Federal Reserve Bank of San Francisco Econotnic Review (Spring 1983), pp. 12-19; and Milton Friedman, "Why a Surge of Inflation is Likely Next Year, "Wall Street Journal, September 1 , 1983. Though these economists generally agree on the factors affecting velocity, they disagree on the relative importance of the factor's cited.

${ }^{20}$ The Tatom modet has a smaller root-mean-squared error than the best univarate tine series model recently reported by fiein and Veagelers, as well as a model which explains velocity growth with movements in real interest rates and the expected rate of inflation alone. See Tatom, "Was the 1982 Velocity Decline Urustal?"; and Soott E. Hein and Paul T. W. M. Veugelers, "Velocity Growth Predictability: A Time Series Perspective," this Review (October 1983), pp. 34-43.

${ }^{21}$ That is, approximately 95 percent of the intervals so constructed in one quarter would contain the value of velocity in the next. This simplified interpretation of the forecast interval tends to understate the margin of forecast error. See Robert S. Pindyck and Daniel L. Mubinfeld, Econometric Models and Economic Forecast.s (McGraw Hill, 1976), chapter 6.

${ }^{22}$ This result implies that recent suggestions that the Federal Reserve use nominal GNP as an intermediate target are illadvised. 


\section{SUMMAET AND CONCUUSIONS}

This article outlines the meaning of income velocity and reviews its important role as the link between money growth and nominal GNP growth. It demonstrates the problems that the monetary authority faces if it attempts to offset short-run (quarter-to-quarter) changes in velocity growth. Indeed, it appears that, even if a conservative estimate of the one-quarterahead forecast standard deviation is used, the forecast errors are large for policy purposes. Thus, while it might seem desirable for the monetary authority to respond to permanent changes in the level or growth rate of velocity, it is difficult to predict such changes, or to verify them quickly ex post.

\section{Appendix: Cyclical Factors That Affect Velocity}

The purpose of this appendix is to illustrate four factors that can produce movements in velocity associated with cyclical swings in GNP.

\section{Mensured Vs. Theorentical Velocity}

Velocity as it is usually measured may differ from its theoretical counterpart. As a result, not all changes in measured velocity indicate true changes in velocity. To illustrate this, consider the common specification of the demand for nominal money,

$$
M^{d}=f\left(P, \dot{p}^{e}, r, r^{e}, Y_{p}, Z\right)
$$

where

$$
\begin{aligned}
& \mathrm{P}=\text { the current price level } \\
& \dot{\mathrm{p}}^{\mathrm{e}}=\text { the expected future price level } \\
& \mathrm{r}=\text { the current real interest rate } \\
& \mathrm{r}^{\mathrm{e}}=\text { the expected future real interest rate } \\
& \mathrm{Y}_{\mathrm{p}}=\text { current nominal permanent income } \\
& \mathrm{Z}=\text { all other factors that affect money demand. }
\end{aligned}
$$

It is usually assumed that individuals do not suffer from a money illusion (i.e., equation A. 1 is homogenous of degree one in $P$ and $Y_{p}$ ) so that equation $A . l$ can be written as

(A.2) $\mathrm{M}^{\mathrm{t}} / \mathrm{P}=\mathrm{f}\left(\dot{\mathrm{P}}^{\mathrm{e}}, \mathrm{r}, \mathrm{r}^{\mathrm{e}}, \mathrm{Y} / \mathrm{p}, \mathrm{Z}\right)$

or

\footnotetext{
'See Milton Friedman, "The Otantity Theory of Money: A Restatement, in Studies in the Quantity Theory of Money (University of Chicago Press, 1956
}

(A.3) $\mathrm{m}^{\mathrm{d}}=\mathrm{f}\left(\dot{\mathrm{P}}^{\mathrm{e}}, \mathrm{r}, \mathrm{r}^{\mathrm{e}}, \mathrm{y}_{\mathrm{p}}, \mathrm{Z}\right)$,

where $\mathrm{m}^{\mathrm{d}}$ denotes the demand for real money balances and $y_{p}$ denotes real permanent income. Now assume that A. 3 is homogenous of degree s in real permanent income so that A. 3 can be written as

(A.4) $\mathrm{m}^{\mathrm{d}} /\left(\mathrm{y}_{\mathrm{p}}\right)^{\mathrm{s}}=\mathrm{f}\left(\dot{\mathrm{P}}^{\mathrm{e}}, \mathrm{r}, \mathrm{r}^{\mathrm{e}}, \mathrm{Z}\right)$.

Further assume that $s=1$, so that the theoretical measure of velocity, $\mathrm{V}^{*}$, is

$\mathrm{V}^{*}=\mathrm{Y}_{\mathrm{r}} / \mathrm{M}=\mathrm{l} / \mathrm{f}\left(\dot{\mathrm{P}}^{e}, \mathrm{r}, \mathrm{r}^{\mathrm{e}}, \mathrm{Z}\right)$.

Thus, if velocity is measured as $\mathrm{Y} / \mathrm{M}$, changes in measured velocity can occur that do not reflect changes in $V^{*}$. Of course, estimates of $Y_{p}$ could be used to get a better estimate of $\mathrm{V}^{*}$; however, this problem will continue to the extent that there are estimation errors. Moreover, the most commonly watched measure of velocity is $\mathrm{Y} / \mathrm{M}$.

\section{Economies of Scale}

Another problem arises when $s \neq 1$. It is sometimes argued that the elasticity of the demand for real money balances with respect to real permanent income is less than one. If this is the case, the percentage change in real money balances will be less than the percentage change in real income. An increase in real income will result in a less than proportionate increase in the holding of real money and, hence, an increase in velocity. Thus, if there are cyclical movements in permanent income, velocity would rise during the expansion phase of the cycle and fall during the contraction phase. This would occur even if permanent income 
were measured precisely. This factor also could account for a secular rise in velocity as real output expands. For example, if real output is growing at a 4 percent rate and the real income elasticity of the demand for real money is about one-half, then velocity would grow secularly at about a 2 percent rate.

\section{Short-Run Adjustments of Money Demand}

Another factor that can account for cyclical movements in velocity is the possibility of short-run adjustments of money demand. A change in one of the factors in $\left.f()^{\circ}\right)$ alters an individual's demand for real money while leaving his actual holdings of real money unchanged. As a result, the individual must adjust actual money holdings to his new desired holdings. Such an adjustment is costly, so the adjustment may progress (perhaps slowly) over time. Theoretically, the speed at which this portfolio adjustment takes place depends on the cost of moving to the new equilibrium relative to the cost of being out of equilibrium: the higher the former cost relative to the latter, the slower the speed of adjustment. ${ }^{2}$ If these adjustment costs are small, the adjustment will be rapid; however, most empirical estimates suggest a very slow adjustment. ${ }^{3}$ In any event, if money demand does not adjust immediately,

\footnotetext{
${ }^{2}$ See Zvi Griliches, "Distributed Lags: A Survey," Econometrica (January 1967), pp. 16-49.

${ }^{3}$ For a discussion of this problem and some estimates of the speed of adjustment, see Daniel L. Thornton, "Maximum Likelihood Estimates of A Partial Adjustment-Adaptive Expectations Model of the Demand for Money," Review of Economics and Statistics (May 1982), pp. 225-29.
}

an increase in real income can produce a smaller increase in the demand for money in the short run and, hence, a short-run increase in velocity. As the demand for money adjusts towards the new equilibrium, velocity will approach the level implied in A.4.

The above analysis rests in a disequilibrium between actual and desired money holdings. If such disequilibria exist, they also could be caused by real-side shocks, such as natural disasters, oil price shocks and the like.

\section{Lags in the Effect of Money on Nominal Income}

Another possibility is a lag effect from money to income. ${ }^{4}$ That is, changes in the current money stock produce changes in nominal income with a lag that is distributed over several quarters. If this is the case, a change in the current money stock produces a less than proportional change in current nominal income and, hence, an initial decline in velocity. Thus, periods of relatively rapid money growth tend to be associated initially with declining velocity, while periods of relatively slow money growth tend to be associated initially with rising velocity. Taking this factor and previously mentioned factors into consideration, it could be argued that the decline in velocity during 1982 was precipitated by the decline in real economic activity and exacerbated by the rapid growth of $\mathrm{Ml}$ beginning III/1982.

${ }^{\text {IIf }}$ money were exogenous, then this lag would only result from a lagged response of money demand, swoh as that discussed above. In this instance, this and the previous factor would be identical. 